\title{
Além dos muros manicomiais: conhecendo a dinâmica das residências terapêuticas*
}

\author{
Beyond the madhouse walls: knowing the dynamics of the therapeutic residences
}

Además de las paredes de los manicomios: conociendo la dinámica de las residencias terapéuticas

\section{Hudson Pires de Oliveira Santos Junior', Maria de Fátima de Araújo Silveira', Chirlaine Cristine Oliveira'}

'Universidade Estadual da Paraíba. Faculdade de Ciências Médicas. Campina Grande, PB

Submissão: $08 / 04 / 2008$

Aprovação: 02/03/2009

\section{RESUMO}

Trata-se de um estudo com abordagem Qualitativa, cujo objetivo foi buscar a visão da equipe de profissional sobre a experiência de implantação das Residências Terapêuticas no município de Campina Grande-PB. Utilizamos para coleta de dados à observação sistemática, o diário de campo e o roteiro de entrevista semi-estruturada, a qual foi aplicada a 10 profissionais atuantes nas residências. Como resultado da análise de conteúdo das entrevistas, identificamos as seguintes categorias analíticas: as várias concepções sobre a saúde mental; como se dá o cotidiano nas Residências Terapêuticas; as dificuldades encontradas pelos profissionais na prática do cuidado; bem como as perspectivas desses para os usuários.

Descritores: Saúde Mental; Enfermagem psiQuiátrica; Sanatórios psiQuiátricos.

\section{ABSTRACT}

This is a study with Qualitative approach, whose objective was to look for the vision of professional's team about the experience of implantation of the Therapeutic Residences in the municipal district of Campina Grande, PB, Brazil. For data collection the systematic observation, field diary and a semi-structured interview were used, which was applied to 10 active professionals in the residences. As a result of content analysis of the interviews, the following analytical categories were identified: the several conceptions about the mental health; the daily activities in therapeutic residences; the difficulties found by the professionals in practice of the care; as well as the perspectives of those for the users.

Descriptors: Mental health; Psychiatric nursing; Hospitals, psychiatric.

\section{RESUMEN}

Tratase de un estudio con enfoeue cualitativo, cuyo objetivo fue buscar la visión del equipo de profesional sobre la experiencia de la implantación de las Residencias Terapéuticas (RT) en el distrito municipal de Campina Grande - PB. Usamos para la coleta de dados la observación sistemática, el diario de campo e el intinerário de entrevistas estructuradas, la cual fue aplicada 10 profesionales actuantes en las residéncias. Como resultado de las análisis del contenido de las entrevistas, identificamos las siguientes categorías analíticas: los varios conceptos sobre la salud mental; como darse el cotidiano en las RT; los apuros encontrados por los profesionales en la práctica del cuidado; tambien las perspectivas de ésos para los usuarios.

Descriptores: Salud mental; Enfermería psieuiátrica; Hospitales psiQuiátricos. 


\section{INTRODUÇÃO}

O início da Reforma Psieuiátrica no Brasil é contemporâneo ao surgimento do movimento sanitário do final dos anos 70, porém, organizando-se com base nos pressupostos da experiência Italiana de desinstitucionalização em psiquiatria e na sua crítica ao manicômio, visando à desconstrução do modelo manicomial ${ }^{(1,2)}$.

Porém, a tentativa de legalização de tal Reforma ocorreu somente em 1989, com a apresentação do Projeto de Lei 3.657/89. Sendo aprovado e transformado na Lei 10.216, em Abril de 2001. A Qual garante o processo de substituição progressiva dos leitos em hospitais psiquiátricos por uma rede comunitária de atenção psicossocial $^{(3)}$.

Contudo, a desinstitucionalização e a efetiva reintegração dos sujeitos adoecidos mentalmente na comunidade necessitam de uma rede integrada de apoio, Que tem o Programa de Saúde da Família (PSF) como porta de entrada para o sistema de saúde.

Para responder a tal necessidade, foram criados Programas de Saúde Mental para a implantação do novo modelo assistencial extrahospitalar, composto por serviços agenciadores e estratégicos: o Hospital-dia, leitos em Hospitais Gerais, Centros de Apoio Psicossocial (CAPS), Centro de Convivência e Cultura, Mini-equipes de saúde mental nos PSF, Serviços de Urgência e Emergência em saúde mental e Serviços de Residências Terapêuticas (SRT) ${ }^{(1)}$.

Dentre esses dispositivos de atenção, destacamos as Residências Terapêuticas, as Quais têm por objetivo oferecer um novo tipo de atenção para ex-internos/as Que não contam mais com apoio de familiares para voltar à comunidade ou cujas famílias não mais os aceitam, sendo instituídas pela Portaria $106 / 2000^{(3)}$.

Todavia, vale salientar Que não se trata precisamente de um serviço de saúde, mas de espaços para morar e viver, onde a admissão de um morador é o começo de um longo processo de reabilitação, Que deverá buscar sua progressiva inclusão social e emancipação pessoal, afinal, sua finalidade principal é a moradia, o morar e o viver na cidade ${ }^{(4)}$.

Para tanto, cada moradia deve ser considerada única, sendo organizada segundo as necessidades, gostos e hábitos de seus moradores, tendo sempre em mente, Que as residências têm seu tratamento centrado no modelo humanista, visando oferecer vivências enriQuecedoras Que promovam maior capacidade para os indivíduos enfrentarem os desafios da vida.

Devido a essas particularidades, a implantação das moradias vem sendo debatida em vários âmbitos, de maneira a garantir Que esta alternativa seja a mais eficaz possível para auxiliar o morador em seu percurso, muitas vezes complicado, de reintegração à comunidade, buscando a progressiva inclusão social e sua emancipação pessoal, afinal, a finalidade principal é a moradia, o morar e o conviver na comunidade ${ }^{(4)}$.

Diante dessa realidade, este estudo teve por objetivo: conhecer como vem se desenvolvendo a experiência de implantação da Residência Terapêutica na visão da equipe.

\section{METODOLOGIA}

Trata-se de uma pesquisa com abordagem Qualitativa. Um dos argumentos para apoiar o uso da pesquisa Qualitativa é Que a mesma possibilita lidar com o significado atribuído pelos sujeitos aos fatos, relações, práticas e fenômenos sociais.

O estudo foi realizado em Campina Grande, cuja população é de cerca de 370.000 habitantes, localizando-se no interior do estado da Paraíba, devido ao fato deste município estar experimentando e implementando medidas para a desinstitucionalização de pessoas com internações psiQuiátricas de longa permanência. Tal processo se iniciou Quando o Ministério da Saúde instituiu o Programa Nacional de Avaliação do Sistema Hospitalar/ Psiquiatria 2003/2004. Um dos resultados da avaliação foi a desclassificação e o descredenciamento de oito hospitais no país, entre os Quais estava um nesta cidade, e Que respondia a grande parte da demanda de saúde mental da região geopolítica do Compartimento da Borborema/PB. A intervenção ocorreu com a desospitalização dos 176 internos, em Abril de 2005, e terminou em Julho do mesmo ano, com o descredenciamento do hospital da Rede SUS

Campina Grande passou, então, a receber incentivos financeiros do Ministério da Saúde para a implantação de Centros de Apoio Psicossocial, Residências Terapêuticas e outros serviços de atenção à saúde mental. Em cerca de um ano, este município conseguiu reverter seu modo de atenção à saúde mental, passando do modelo hospitalocêntrico para o modelo de atenção psicossocial.

No cenário atual, a cidade possui uma rede ampla de serviços substitutivos, sendo esses: 0I CAPS II, 0I CAPS III, 02 CAPSi (infantis), 01 CAPSad (álcool e outras drogas), 01 Unidade de Emergência Psiquiátrica, 01 Centro de Cultura e Lazer, 09 Miniequipes de saúde mental nos PSF e 06 Residências Terapêuticas.

A inauguração das primeiras residências no município ocorreu, inicialmente, em setembro de 2005, com a implantação de três moradias, denominadas de acordo com o gênero de seus usuários, como: Residência Terapêutica Feminina I e Feminina Il e Residência Masculina I. Ainda devido à necessidade de criação de novas residências, foram inauguradas, em maio de 2006, mais três moradias, também denominadas pelo mesmo critério das pioneiras, sendo então chamadas de: Residência Terapêutica Masculina II e Masculina III e Residência Mista.

Como atores da investigação do presente estudo, estão 10 profissionais Que atuam na equipe das seis Residências Terapêuticas do município: 01 coordenador, 02 técnicos de referência e 07 cuidadores. A identificação dos entrevistados nos discursos se faz da seguinte forma: Prof. (para o entrevistado) e o número para identificação do participante, seguindo o critério de ordem de realização da entrevista. Os profissionais não foram identificados por categoria, para assegurar o anonimato dos mesmos, pois como se tratava de um grupo pequeno e o local da pesquisa também, seria fácil identificar os autores dos discursos.

Em relação ao perfil profissional dos entrevistados: 03 possuem capacitação em saúde mental e, desses, apenas 01 tem experiência com sofredores psíquicos; 07 não possuem capacitação para atuar na saúde mental, e desses, 05 sequer tiveram algum tipo de experiência com sofredores psíquicos, antes de atuarem nas moradias. Os 03 profissionais Que afirmam terem recebido capacitação, relatam Que houve apenas uma durante o período Que atuam nas Residências Terapêuticas.

Em fase prévia à coleta de dados, foi realizada uma reunião com a equipe do Serviço de Residência Terapêutica, na Qual a proposta de pesquisa foi apresentada, com seus objetivos, o modo como 
seria executada, bem como com a apresentação dos pesquisadores e o convite para participação do estudo. Após esse primeiro contato, buscamos os profissionais interessados em colaborar e, por meio do telefone, era marcado um local e data para realização da entrevista Que, geralmente, ocorriam nas próprias Residências Terapêuticas.

Os dados foram obtidos durante o período de Dezembro a Fevereiro de 2007, por meio de: observação sistemática, Que teve o objetivo de captar informações sobre a realidade investigada em seu próprio contexto; diário de campo, onde foi feito um registro das observações de cunho descritivo e reflexivo; e roteiro para entrevista semi-estruturada, as Quais foram executadas e gravadas, com o prévio consentimento dos participantes, por meio da assinatura do Termo de Consentimento Livre e Esclarecido.

No tratamento dos dados, os discursos dos participantes foram submetidos à Análise de Conteúdo, do tipo temática ${ }^{(5)}$, Que tem como intuito realizar uma interpretação das entrevistas Que supere o nível do senso comum e do subjetivismo, alcançando uma vigilância crítica frente a esse material, cujo produto esta apresentado em categorias, ilustradas com discursos e recortes de falas dos (as) profissionais.

O desenvolvimento do estudo seguiu as normas da Declaração de Helsinki, de 1975, na versão de 2000, e as diretrizes emanadas da Resolução 196/96 do Conselho Nacional de Saúde ${ }^{(6)}$, Que regulamenta as normas aplicadas a pesquisas Que envolvem Seres Humanos e, para a sua operacionalização, o projeto foi submetido à apreciação do Comitê de Ética em Pesquisa da Universidade Estadual da Paraíba, só sendo executado após anuência desse órgão (Protocolo 021 1.0.133.000-06).

\section{RESULTADOS E DISCUSSÃO}

\section{Análise das Categorias}

Após a análise do conteúdo das entrevistas, foi possível identificar as categorias analíticas Que se segue:

"O cotidiano nas residências é dentro dos limites deles"

A assistência a sofredores psíquicos por meio das Residências Terapêuticas, teve como uma das representações, trazer consigo maiores chances de recuperação para os usuários, configurandose, portanto, em uma proposta adequada para tal fim:

\section{É muito importante pra eles, tem uns Que já tão bem evoluído} (PI0).

Eles não tinham a atenção Que estão tendo aQui (P7).

É salutar a importância Que as moradias têm na terapêutica e na ressocialização de egressos de instituições asilares, pois cumprem importante função educativa e de referência para seus moradores, os Quais têm suas fantasias e receios reduzidos Quando passam a ter contato com o contexto social(9).

Para alguns atores desta investigação, o modo como as residências assistem seus usuários se dá de modo mais humanizado:

A questão que acho nessa proposta de trabalho, é a Questão humana, então, no outro lado se viu mais a parte técnica e nesse novo modelo a gente percebe que é uma coisa mais humanizada (PI).
Humanizar é antes de tudo, considerar as necessidades e desejos individuais de cada pessoa, ofertando as condições necessárias para Que esta seja sujeito da sua história. Esse novo enfoque - psicossocial rompe com o modelo segregador e oneroso das instituições psieuiátricas, Que se assemelham mais a uma linha de montagem industrial, na Qual, as tarefas e, o Que é mais grave, o sujeito, são fragmentados e encadeados como Qualeuer mercadoria da produção comum ${ }^{(10)}$.

Uma outra representação sobre a proposta de atenção oferecida nas moradias, é a concepção do "cuidar". Os depoimentos pontuam a dessasistência ao sofredor psíquico no modelo hospitalocêntrico e, afirmam Que a atenção a essas pessoas se tornou efetiva através da prática de cuidados disparada pelo domicílio:

$A h$, isso foi muito bom viu? Primeiramente lá no hospital $X$ não tinha nenhuma condição, [...] era muito precário lá e aQui melhorou 100\% pra eles (P6).

No hospital eles viviam muito abandonado. Além de ter a solidão, era as condições de moradia, de higiene, aQui o cuidado melhorou muito (P8).

Essa mudança se dá porQue a operação do cuidado na moradia envolve todo o contexto singular do usuário(7) (sua casa, seu espaço, seus pertences, seus vizinhos, seus companheiros), o que possibilita a produção de cuidado mais próximo e individualizado.

Uma das principais características da nossa sociedade é a falta de segurança na vida em grupo. $\mathrm{O}$ isolamento emocional do indivíduo e a necessidade de pertencer a uma coletividade são profundos e as frustrações de não conseguir são vastas. Quando se fala de pessoas Que apresentam transtornos psíquicos, esses sentimentos são mais observados, pois sua história já vem marcada por abandono, estigmas e exclusões ${ }^{(1)}$. Todavia, os usuários das residências vêm conseguindo, na medida do possível, superar esse estigma, começando a criar vínculos sociais e de amizade, com os seus colegas de moradia e até mesmo com as pessoas da comunidade local:

A convivência é normal, até porQue eles já conviviam no hospital $X,[\ldots]$ e hoje estão em número reduzido por residência. Então [...] eles são muito familiares uns com os outros (P3).

O pessoal da rua tudinho já sabe o nome de todos. O pessoal passa, fala com todo mundo, os meninos aí da frente também brincam com eles (P8).

Acreditamos Que um novo contexto de cidadania para portador de transtorno mental, só se concretiza no momento em Que se pode dar-lhes o real direito de cidadão ${ }^{(12)}$. Não de ser excluído, violentado, descriminado, mas de receber ajuda em seu sofrimento e permitir Que sejam sujeitos de desejos e projetos, como propõe as Residências Terapêuticas.

Um aspecto comum observado diz respeito à variação de humor/ comportamento de alguns usuários das residências, podendo, em determinado instante, estar alegre e, em instantes seguintes agressivos:

Eles são muito amigos, conversam bastante, às vezes, porQue 
ocorre Quando eles não tão nos dias bons deles, às vezes, assim eles cismam até comigo mesmo, mas não tem essa coisa de tá brigando, não (P7).

Os discursos relatam mudanças súbitas e inexplicáveis de atitude - um dia, calmo e amigável; no outro, rude e, até mesmo, violento. Todavia, é preciso considerar Que muitos dos sofredores psíquicos Que têm passado a viver nas moradias ficaram, em geral, vários anos internados ${ }^{(13)}$. As longas décadas de reclusão promoveram significativas experiências de "desenraizamento" da cidade e de suas tradições culturais. São indivíduos Que foram apartados de seus territórios, de suas famílias, grupos sociais e, sobretudo, de seus direitos sociais e civis fundamentais.

Devido à esta prática de segregação e exclusão do sofredor psíQuico todas as atividades realizadas nas Residências Terapêuticas, têm, como fator condicional, os seguintes objetivos centrais e oficiais: promover a reinserção social, proporcionando-lhes autonomia, através do processo de reabilitação psicossocial, com reaprendizagem de atividades cotidianas e sociais necessárias para a vida em comunidade ${ }^{(4)}$.

A gente sempre leva à missa, leva à praça, ao shopping, ao comércio, pra fazer compras, pra o banco, pra INSS, pra passar fim de semana com a família, aqueles Que têm e aqueles Que também Querem (P3).

Trata-se de reinventar a vida em seus aspectos mais comuns ${ }^{(14)}$, pois é do cotidiano da cidade, principalmente, Que se encontram privados os sofredores psíeuicos. Portanto, essa forma de cuidado oferece aos sujeitos um cotidiano mais dinâmico, como mostra o discurso Que se segue:

...tem um que depois do almoço os pratos é dele, ele lava melhor do que eu, aí tem um que limpa a mesa, tem um Que Quer varrer a casa, um todos os dias pra varrer a frente é dele, aí fala com os vizinhos. Tinha um Que ele era muito preguiçoso, só fazia dormi, dormi, hoje em dia me ajuda bastante (P7).

Ainda no cotidiano das moradias é feito um trabalho de aprendizagem e estimulação do usuário para o auto-cuidado, Que segundo a definição ${ }^{(15)}$, é uma prática de atividades Que os indivíduos iniciam e executam em seu próprio benefício, para a manutenção da vida, da saúde e do bem-estar, já tendo alguns usuários Que assumem essa tarefa integralmente e outros parcialmente:

Esse tipo de atividade deles mais de corpo, essa história de escovar dentes, tomar banho, eles, a maioria das vezes fazem só, Que é um avanço muito grande, porQue eles saíram do hospital não conseguiam fazer isso de maneira nenhuma,... esse foi um fato, Que foi ensinar a eles como se fosse uma criança, a escovar dentes, a lavar cabelo, a limpar o ouvido. Esse tipo de coisa foi muito lento, mas a maioria deles hoje consegue fazer só (P3).

De acordo com esse discurso, Quando os usuários ingressaram nas residências, foi necessário incentivar o reaprendizado do autocuidado "como se fosse uma criança", isso porque, no modo asilar a terapêutica não implica no investimento da mobilização do usuário como participante do tratamento, sustentando-se ainda na hipótese de Que Quem trabalha e cuida, basicamente, é o remédio ${ }^{(10)}$.

Outro ponto Que não podemos deixar de considerar é a sobrecarga Que recai sobre os familiares por terem de acompanhar e cuidar de seus membros adoecidos. Essa sobrecarga poderá advir do medo, da responsabilidade com o cuidado, da culpa, da frustração ${ }^{(13)}$, enfim, da dificuldade de lidar com a complexidade Que envolve a situação. No entanto, há casos em Que a família é a cuidadora. Nesses casos, a figura da mãe é que tem maior destaque e atuação, ocasionando, assim, acúmulo de atribuições e encargos maternos:

A mãe de um usuário lá, ela vem todo dia da banho nele, lava cabelo, corta unha, mas as outras vão geralmente uma vez no mês. Tem usuário que desde que saiu do hospital, há dois anos a família nunca foi visitar (P3).

Para explicar o papel isolado da mãe no cuidado ao sofredor psíquico, nos remetemos à história da doença mental ${ }^{(16)}$ : no início do "problema", irmãos, parentes e mesmo vizinhos mobilizam-se em torno do evento, buscam soluções e envolvem-se efetivamente no cuidado; à medida Que o tempo passa e a doença se transforma em rotina, o interesse e a participação prontamente decrescem e elas, mães, são deixadas sozinhas na administração dos cuidados, sendo, em seguida, transferidos, na maior parte das vezes, para as instituições psiQuiátricas.

Para evitar tal desfecho as ações dos serviços substitutivos ao hospital psiquiátrico, devem compor uma rede comunitária de cuidados, Que se articulem entre os variados dispositivos extrahospitalares, família e sociedade formando um conjunto vivo e concreto de referências capazes de acolher as pessoas em sofrimento mental ${ }^{(1)}$.

É, a gente mantém uma parceria boa com o CAPS, com a Emergência Psiquiátrica e com o Serviço Municipal de Saúde, e com outros serviços, como PSF e o Centro de Convivência (P2).

Dentro desse contexto os moradores das residências são levados duas vezes por semana para o Centro de Apoio Psicossocial de referência. Lá, participam de oficinas, interagem com outros usuários, desenvolvem trabalhos artísticos, bem como praticam atividades físicas. O Centro de Convivência é um local de lazer e profissionalização, além de permitir, também, Que os usuários entrem em contato com a comunidade, devido ser aberto ao público. $\mathrm{O}$ Programa Saúde da Família destina-se aos usuários que necessitam de consultas clínicas e exames, bem como é a porta de entrada do Sistema Único de Saúde e serve como articulador entre a família, comunidade e usuário; as Unidades de Emergência Psiquiátrica entram nesse cenário Quando o usuário está em crise, e a mesma não é aliviada por meios não medicamentosos.

\section{A dificuldade Que eu acho nas residências é...}

No interior de um novo paradigma e de uma nova prática à saúde, Que envolve a desospitalização e a implementação de iniciativas para reinserir o sofredor psíquico em seu meio social e familiar, buscou-se identificar Quais são as principais dificuldades encontradas pela equipe do Serviço de Residência Terapêutica dentro da lógica antimanicomial. Como respostas encontradas, a primeira 
é a "ausência de dificuldades":

Pra mim, até agora, não tenho dificuldade nenhuma (P5); Bom, até agora, eu não encontrei nenhuma dificuldade, pra diferença do hospital $X$ que a gente teve lá, aqui tá tudo perfeito (P6).

Acredita-se que um dos fatores Que contribuem para maior satisfação entre os profissionais, é o fato de atuar em um projeto assistencial "novo" e com status diferenciado ${ }^{(17)}$, como é o caso das moradias.

Todavia houve relatos Que apontaram dificuldades presentes na dinâmica das moradias, como a falta de capacitação profissional, já mencionada:

A dificuldade que eu encontro nessa prática é a Questão da capacitação, Que é preciso ter mais capacitação continuada pra os profissionais Que trabalham com saúde mental (P3).

Embora o Ministério da Saúde tenha criado Núcleos ou Pólos Regionais de Capacitação e Produção de Conhecimento em diversas localidades do país, observou-se Que alguns deles ainda estão em fase de implantação, e os Que já estão instalados são recentes e têm organizado poucos cursos, mesmo assim de forma não sistematizada e centralizados nos grandes centros urbanos ${ }^{(1,18)}$.

Outra dificuldade apontada é em relação ao "tempo insuficiente para o cuidar", particularmente, nos discursos dos cuidadores:

A dificuldade que eu acho nessas residências, é Que a gente não tem muito tempo pra dizer... cuidador. A função de cuidador é, realmente, é cuidar deles, dar atenção a eles e como a gente aQui toma conta da casa e deles, não sobra muito tempo pra eles... às vezes, eles Querem brincar, às vezes, a gente Quer ensinar, a gente não tem tempo de brincar com eles, eles cobram muito isso da gente... Eles Querem muita atenção e a gente não tem como dar (P7).

A interação do cuidador com os usuários é fator de grande influência na recuperação e reabilitação(19), pois permite Que o profissional conheça as dificuldades concretas e materiais do que significa viver como sofredor psíquico.

Outra dificuldade refere-se ao "pouco suporte e estrutura" nas Residências Terapêuticas:

A única dificuldade que eu encontro, é a dificuldade de trabalho. A gente não tem um carro disponível pra trabalhar, a gente dispõe apenas de uma Kombi para transportar 45 usuários. Então, se eu tiver carro próprio, eu vou ter que trabalhar nele, se eu não tiver, eu vou ter que trabalhar a pé, de ônibus, de moto-táxi, então fica difícil, entendeu? (P3).

Essa carência de recursos guia o olhar para a necessidade de compreensão dos recursos financeiros do Serviço de Residências Terapêuticas municipal. Em um levantamento, constatou-se Que as residências possuem um gasto mensal de $\mathrm{R} \$ 40.500,00$, o equivalente a $\mathrm{R} \$ \mathbf{9 0 0 , 0 0}$ por morador. Segundo o Sistema de Informação Hospitalar (SIH), o valor médio de uma Autorização de Internação Hospitalar (AIH) de saúde mental, encontra-se em torno dos $R \$ 700,00$. Tais valores explicitam Que as Residências Terapêuticas não são equipamentos de custo baixo em relação ao custo hospitalar. Pois, se a lógica da Reforma Psieuiátrica fosse racionalizar recursos econômico-financeiros, não seria vantajoso investir nesses dispositivos e na implantação de uma rede substitutiva ${ }^{(12)}$.

O foco está em promover uma chance de resgate de vida aos sofredores psíquicos, de reconhecimento enquanto sujeito, de cidadanização, de desobjetivação paralisadora Que a instituição asilar imprime $^{(7)}$. Poder retomar o convívio social em uma casa, requer dessas práticas um custo de um valor sem preço.

\section{As perspectivas para os usuários não deve ser diferente}

Entre as perspectivas Que a equipe das Residências Terapêuticas apresenta em relação aos usuários, uma se relaciona com o desejo de reinserir socialmente os moradores, pois, apesar desses sujeitos estarem fora dos muros hospitalares, há ainda outros muros a superar ${ }^{(20)}$, Que são os construídos pelo vazio e pela falta de laços sociais:

A gente espera Que eles voltem a conviver no seu lar, com a sua família, Que pra eles, vai ser bem melhor voltar a viver dentro do seu próprio lar, sendo essa a expectativa da saúde mental (P7).

A segunda perspectiva apontada pela equipe do Serviço de Residências Terapêuticas, é o anseio de inserção dos usuários no mundo do trabalho:

Esperamos que eles tenham condições de até chegar a ter um emprego, se alguma empresa desse essa chance, oportunidade, pra eles ficar em uma atividade Que não tivesse perigo, alguma coisa, Quem sabe cumprir um horário como uma jornada de trabalho (P9).

O significado do trabalho na atribuição de normalidade ou melhora, possui três aspectos importantes ${ }^{(16)}$ : em primeiro lugar, a disposição para o trabalho está relacionada à força - entendendose como estado de plena posse de capacidades físicas e mentais. A concepção do Que é ser trabalhador se relaciona, também, ao cumprimento de expectativas sociais. Mas do Que isso, o exercício do trabalho é tido como participante e mantenedor de redes de reciprocidade no interior da família, o Que geralmente se Quebra Quando do surgimento da doença mental. O trabalho possui a capacidade de tornar os sujeitos em agentes ativos no mundo em Que vivem e não apenas espectadores passivos ou submissos ${ }^{(17)}$.

A auto-administração/autonomia surge como terceira, mas não menos importante, perspectivas dos profissionais em relação aos usuários, sendo bem representada pelo discurso a seguir:

O principal é tentar fazer com Que eles possam, eles morem sozinhos, eles mesmo cuidem da casa, façam alimentação deles, o técnico vai ficar só observando, mas eu acho que tem que ser um período muito grande. Já tem residência Que eles moram só, vão ao supermercado e a proposta de todas as residências é a mesma (P8).

Esse modo de viver nas residências tem possibilitado aos 
moradores um ganho de autonomia Que faz toda a diferença na vida de cada um. Há moradores que já circulam pelo território de uma maneira mais autônoma, com inserção na escola, em grupos religiosos:

Tem um morador que ele já estuda, ele freqüenta a igreja evangélica, ele freqüenta a terapia do amor, já fez cartão do $Y$, cartão da $Z$, ele é bem desenrolado mesmo, ele participa mesmo da sociedade, vai pro centro com suas coisas, é assim! (P9).

Limpar um jardim, comprar mercadorias, descobrir as maneiras de interagir com as pessoas, desenvolver um trabalho, fazer amizades, descobrir os direitos, encontrar um namoro, ir à igreja, acompanhar o movimento da cidade, são estratégias dotadas de fundamental capital afetivo e simbólico Que ajudará o sofredor psíquico no resgate da sua cidadania ${ }^{(21)}$.

Logo, é importante fecundar a concepção de cidadania ${ }^{(22)}$, na Qual ser cidadão não implica apenas em reconhecimento de direitos, mas sim um processo ativo de ampliação da capacidade de autonomia e liberdade, de modo Que a "loucura" não signifieue limitações e incapacidades.

\section{CONSIDERAÇÕES FINAIS}

A Reforma Psiquiátrica se constitui em um processo Que inclui movimentos sociais e políticos, Que desconstruiram tanto o conceitos de saúde em geral, como os de prática em psieuiatria, em particular. Devido a esse panorama, elegemos a saúde mental, para pesQuisar, com o intuito de contribuir tanto para a discussão do tema, Quanto para o aprimoramento dos serviços extra-hospitalares Que lutam para se impor ao modelo hospitalocêntrico predominante, como é o caso do Serviço de Residências Terapêuticas de Campina Grande.

Verificamos Que as residências já são dispositivos consolidados no município, contando com uma rede de serviços substitutivos, a Qual esta ligada à atenção básica e com uma equipe de profissionais multidisciplinar, como é orientado pela proposta da Reforma Psiquiátrica, o que conduz a novas práticas em saúde e abre perspectivas enriQuecedoras, envolvendo o resgate de diálogo entre conhecimento e a realidade de mundo, rompendo com o tradicional e se abrindo ao cotidiano, necessários para a manutenção da saúde mental.

Outro ponto também constatado é o fato de Que mesmo com algumas dificuldades enfrentadas pelos profissionais, como número reduzido de capacitações, ausência da figura familiar do usuário, a eQuipe consegue avançar com o processo de desinstitucionalização, como uma dessas conQuistas tem-se a reformulação das Residências Terapêuticas, Que resultou na organização de uma residência com usuários de elevado grau de autonomia, custeada e administrada em seu cotidiano pelos próprios.

Apesar desses avanços não podemos dizer Que as residências estão ou são a forma ideal de atenção aos sofredores psíquicos, pois ainda são um processo em construção e como tal, faz-se necessário a busca de melhorias. Porém, podemos afirmar que o caminho é o da desinstitucionalização.

Contudo, esta pesquisa não esgota as necessidades de estudo sobre as residências, mas sim, abre nossos horizontes para os vários signos e significados Que permeiam essa prática de cuidado domiciliar, bem como a dos outros serviços substitutivos.

O estudo nos levou a indagação sobre o porquê de uma sociedade defender Que uma parte de seus membros não pode conviver com os demais, cabendo a nós compreendermos os motivos e interagir. Pois, por ser uma Questão de base ética, o futuro da Reforma Psiquiátrica não esta apenas no sucesso terapêutico-assistencial dos novos serviços, mas na escolha da sociedade brasileira, da forma como vai lidar com seus "diferentes", com suas minorias, com os sujeitos em desvantagem social.

\section{REFERÊNCIAS}

1. Ministério da Saúde (BR). Documento apresentado a Conferência Regional de Reforma dos Serviços de Saúde Mental: 15 anos depois de Caracas. Brasília: Ministério da Saúde; 2005.

2. Organização Mundial de Saúde. Relatório sobre a saúde no mundo. Saúde Mental: nova concepção, nova esperança. Genebra: OMS; 2001.

3. Ministério da Saúde (BR). Secretaria de Atenção à Saúde. Legislação em Saúde Mental: 1990-2004. 5ª ed. Brasília: Ministério da Saúde; 2004.

4. Ministério da Saúde (BR). Secretaria da Atenção à Saúde. Residências Terapêuticas: o que são, para que servem. Brasília: Ministério da Saúde; 2004.

5. Bardin L. Análise de conteúdo. Lisboa: Edições 70; 1979.

6. Ministério da Saúde (BR). Conselho Nacional de Saúde. Comissão de Ética em PesQuisa. Resolução 196/96. Dispõe sobre pesquisa envolvendo seres humanos. Brasília: Ministério da Saúde; 1996.

7. Freire FAMA. Residência Terapêutica: inventando novos lugares para se viver [dissertação]. Rio de laneiro: Universidade Federal do Rio de Janeiro; 2006.

8. Antunes SMMO, Queiroz MS. A configuração da reforma psiquiátrica em contexto local no Brasil: uma análise Qualitativa. Cad Saúde Pública 2007; 23(1).

9. Furtado IP. Avaliação da situação atual dos Serviços de Residências Terapêuticas no SUS. Ciência Saúde Coletiva 2006; II (3):

10. Costa-Rosa A. O modo psicossocial: um paradigma das práticas substitutivas ao modo asilar. In: Amarante P. Ensaios: subjetividade, saúde mental, sociedade. Rio de Janeiro: Fiocruz; 2000. p. 141-67.

II. Carvalho AMT, Amarante P. Forças, diferença e loucura: pensando para além do sofrimento da clínica. In: Amarante P. Ensaios: subjetividade, saúde mental, sociedade. Rio de Janeiro: Fiocruz; 2000. p. 4I-52.

12. Amarante P. Novos sujeitos, novos direitos: o debate em torno da reforma psiquiátrica. Cad Saúde Pública 1995; II (3): 49I-4.

13. Weyler AR. O hospício e a cidade: novas possibilidades de circulação do louco. Imaginário 2006 dez; 12(13).

14. Saraceno B. Libertando identidades. Rio de Janeiro: Instituto Franco Basaglia, Te coroá; 1999. 
15. Orem DE. Nursing: concepts of practice. Saint Louis: MosbyYear Book; 1991.

16. Rabelo MCM, Alves PCB, Souza IM. Signos, significados e práticas relativas à doença mental. In: Rabelo $\mathrm{MCM}$, Alves $\mathrm{PCB}$, Souza IM, editores. Experiência de saúde e narrativa. Rio de Janeiro: Fiocruz; 1999. p. 45-73.

17. Vicente B, Vielma M, Jenner FA, Mezzina R, Lliapas I. Attitudes of professional mental health workers to psychiatry. Int I Soc Psychiatry 1993; 39(2): 131-41.

18. Rebouças D, Legay LF, Abelha L. Satisfação como o trabalho e impacto causado nos profissionais de serviço de saúde mental.
Rev Bras Enferm 2007; 2(4I): 31-3.

19. Marzano MLR, Souza CAC. Um relato de experiência de Quem vivencia a reforma psiQuiátrica no Brasil. Rev Bras Enferm 2003; 5 (56): 577-80.

20. Parente ACM, Pereira MAO. Percepção de pacientes psieuiátricos sobre suas famílias: um espelho de dois lados. Rev Bras Enferm 2004; I (47): 44-7.

21. Dalmolin BM. Esperança equilibrista: cartografias de sujeitos em sofrimento psíquico. Rio de Janeiro: Fiocruz; 2006.

22. Oliveira FB, Fortunato ML. Saúde Mental: reconstruindo saberes em enfermagem. Rev Bras Enferm 2003; 1(56): 67-70. 